Original Article (short paper)

\title{
Body composition of male and female Chilean powerlifters of varying body mass
}

\author{
Patricio Palma-Lafourcade ${ }^{1}$, Diego Cisterna ${ }^{1}$, Jordan Hernandez ${ }^{1}{ }^{\circledR}$, Rodrigo Ramirez-Campillo $^{1}$, \\ Cristian Alvarez ${ }^{1}$, Justin W. Keogh $2,3,4(1)$ \\ ${ }^{1}$ Universidad de Los Lagos, Departamento de Ciencias de la Actividad Física, Laboratorio de Rendimiento Humano. Área \\ Prioritaria de Investigación en Bienestar Humano y Calidad de Vida. Osorno, Chile; ${ }^{2}$ Bond University, Faculty of Health \\ Sciences \& Medicine, Gold Coast, Australia; ${ }^{3}$ AUT University, Sports Performance Research Centre New Zealand, Auckland, \\ New Zealand; ${ }^{4}$ Kasturba Medical College, Mangalore, Manipal Academy of Higher Education, Manipal, Karnataka, India
}

\begin{abstract}
Aim: To examine body composition of Chilean powerlifters according to body mass and sex. Methods: Fifty-six male and female powerlifters were recruited from one national competition. Aside from the official weight categories, males were classified as the lightweight, middleweight, and heavyweight classes. Similarly, females were classified as lightweight and middle-heavyweight classes. Nineteen anthropometric measures were assessed, with lean mass as the main outcome. A one-way ANOVA was used to compare groups. Results: Male lightweight class lifted less $(\mathrm{p}<0.01)$ total load $(417 \pm 30.9 \mathrm{~kg})$ compared to heavier male classes $(524 \pm 66.7 \mathrm{~kg}$, middleweight; $581 \pm 131 \mathrm{~kg}$, heavyweight), and female classes lifted less ( $<<0.01)$ total load $(221 \pm 33.8 \mathrm{~kg}$, lightweight; $254 \pm 48.3 \mathrm{~kg}$, middleweight-heavyweight) compared to all male classes. Regarding lean-mass in trunk, arms and legs, total body protein, water, and mineral mass, all male groups had greater $(\mathrm{p}<0.01)$ values than the groups of females, while lightweight males had lower $(p<0.01)$ values than the rest of male groups, and heavyweight males had greater $(p<0.01)$ values than the total sample of males (except for legs lean mass, and total bone mineral content). In females, no significant differences were observed between classes, or in total load lifted or in body composition. Conclusion: Heavier male lifters had significantly greater lean mass than lighter athletes. Therefore, powerlifting performance was affected by anthropometric measures, as corroborated by 1-RM scores. However, there was a general lack of differences in body composition between female weight classes, and, as a result, a lack of differences in 1RM performance.
\end{abstract}

Keywords: muscle strength; strongman; anthropometry; weightlifting; morphology.

\section{Introduction}

Powerlifters compete in various divisions, including those based on body mass and sex, with the aim of lifting the greatest possible loads for one-repetition maximum (1-RM) in the squat, bench press, and deadlift exercises ${ }^{1}$. The current International Powerlifting Federation (IPF) world records reveal that male and female powerlifters have impressive displays of strength, which, although multi-factorial, may be related to anthropometric characteristics $^{2,3}$. Specifically, powerlifters are generally of average to below average height, possess a high body and fat-free mass per unit of height, and have large trunk and limb girths ${ }^{2-5}$. However, due to inter-study differences in data collection and analysis techniques, caution is advised when comparing results between studies. In addition, it is of crucial importance to assess country-specific data due to the potentially different anthropometric characteristics of different ethnic groups so that the data may be used for athlete's talent identification and training program monitoring.

Although the amount of fat-free/lean mass may be the greatest anthropometric determinant of maximal strength ${ }^{2,3,6}$, a range of other anthropometric variables could also influence powerlifting performance. As all powerlifters (with the exception of the superheavyweights, $>125 \mathrm{~kg}$ ) compete in bodyweight divisions that have a maximum allowable body mass, low amounts of body fat are desirable so that the greatest proportion of body mass is useful lean mass rather than fat mass ${ }^{2,3}$. Furthermore, possessing large limb and trunk girths and being highly mesomorphic also appear to be positively related to muscular strength ${ }^{6,7}$. Powerlifters also possess relatively large bony breadths/bone mass ${ }^{4,5,8}$, that may also allow the accumulation of greater lean mass ${ }^{3,6}$.

Consistent with the fact that the IPF events have different bodyweight classes, a true representation of the powerlifting body composition requires a direct comparison of powerlifters across a range of bodyweight categories. While this has been done before in male ${ }^{1,2}$ and female powerlifters ${ }^{9}$, these studies have collected data from Western countries that predominantly included Caucasian powerlifters. Although one study has been reported for Latin-American powerlifters ${ }^{10}$, this study only reported data for male powerlifters. To our knowledge, no study has analyzed the body composition of male and female powerlifters during their peak performance period in non-Western countries. Moreover, no studies on Chilean powerlifters have been reported whatsoever. 
Therefore, the aim of the present study was to examine how body composition of competitive male and female Chilean powerlifters may differ as a function of body mass and sex. It was expected that body composition variables relating to the accumulation of lean mass and fat would increase in male and females from lightweight to middleweight to heavyweight powerlifters. Such results, if found, would support the view that body composition characteristics are important determinants of performance in sports, especially those primarily dependent on one primary motor quality such as muscular strength.

\section{Methods}

\section{Experimental Approach to the Problem}

In order to examine how body composition of competitive male and female Chilean powerlifters may differ as a function of body mass and sex, a cross-sectional study was conducted. Athletes that attended the Annual National Chilean powerlifting championship were requested to participate in 19 anthropometric measures, including trunk and limbs fat and lean mass, total bone mass, protein content, water, total body fat (\%), total fat mass, height, body mass, and body mass index. Aside from the official weight categories in which each participant competes, male powerlifters were classified as a lightweight, middleweight, and heavyweight classes. Similarly, female athletes were divided into a lightweight and a middleweight-heavyweight class. Aside from the anthropometric measures, the competitive performance of athletes was measured, as the total load lifted in the 3 competitive lifts that the competition required (squat; bench-press; deadlift).

\section{Subjects}

Fifty-six Chilean competitive powerlifters participated in the study. Considering the IPF rules ${ }^{11}$, female powerlifters competed in the class up to $47.0 \mathrm{~kg}(\mathrm{n}=2)$, from $47.01 \mathrm{~kg}$ up to $52.0 \mathrm{~kg}(\mathrm{n}=6)$, from $52.01 \mathrm{~kg}$ up to $57.0 \mathrm{~kg}(\mathrm{n}=2)$, from $57.01 \mathrm{~kg}$ up to $63.0 \mathrm{~kg}(\mathrm{n}=4)$, and from $72.01 \mathrm{~kg}$ up to $84.0 \mathrm{~kg}(\mathrm{n}=2)$. Among male powerlifters, recruited participants competed in the class from $59.01 \mathrm{~kg}$ up to $66.0 \mathrm{~kg}(\mathrm{n}=2)$, from $66.01 \mathrm{~kg}$ up to $74.0 \mathrm{~kg}(\mathrm{n}=16)$, from $74.01 \mathrm{~kg}$ up to $83.0 \mathrm{~kg}(\mathrm{n}=6)$, from $83.01 \mathrm{~kg}$ up to $93.0 \mathrm{~kg} \mathrm{(n=6),} \mathrm{from} 93.01 \mathrm{~kg}$ up to $105.0 \mathrm{~kg}$ $(\mathrm{n}=6)$, and from $105.01 \mathrm{~kg}$ up to $120.0 \mathrm{~kg}(\mathrm{n}=4)$. Participants were recruited from one raw national powerlifting competitions held in Chile (Men - Open, and Women - Open). Demographic and performance characteristics of each group of powerlifters are presented in Table 1. According to previous recommendations ${ }^{1,2}$, male powerlifters were further classified on lightweight $(74 \mathrm{~kg}$ and below), middleweight (from $74.01 \mathrm{~kg}$ up to $93.0 \mathrm{~kg}$ ), and heavyweight (from $93.01 \mathrm{~kg}$ and over) classes. Due to the low number of females in the $<47.0 \mathrm{~kg}(\mathrm{n}=2), 52.01 \mathrm{~kg}$ up to $57.0 \mathrm{~kg}$ $(\mathrm{n}=2), 72.01 \mathrm{~kg}$ up to $84.0 \mathrm{~kg}(\mathrm{n}=2)$, and the lack of females in the $63.01 \mathrm{~kg}$ up to $72.0 \mathrm{~kg}$ and $>84.0 \mathrm{~kg}$ weight classes, female athletes were further divided on a lightweight class $(52 \mathrm{~kg}$ and below), while middleweight (from $52.01 \mathrm{~kg}$ up to $72 \mathrm{~kg}$ ) and heavyweight (from $72.01 \mathrm{~kg}$ and over) female classes were mixed.

Table 1. Demographic characteristics of powerlifters (mean \pm standard deviation).

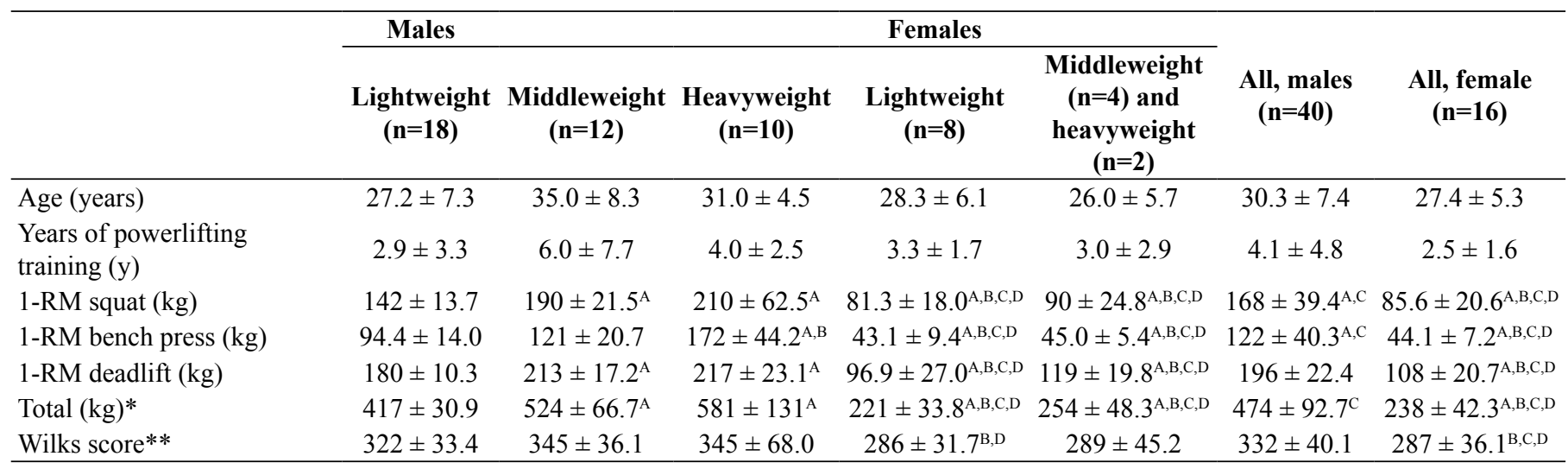

*: sum of the 1-RM squat, bench press, and deadlift; **: calculated from http://wilkscalculator.com/kg; A: different (p<0.05) compared to males lightweight; B: different $(p<0.05)$ compared to males middleweight; $C$ : different $(p<0.05)$ compared to males heavyweight; D: different $(\mathrm{p}<0.01)$ compared to all males.

The highest standard of competition attained by these powerlifters was the Chilean national championship, although one participant attained international competition experience. Therefore, the competitive level was similar across all the bodyweight classes and sex of the athletes. This appears consistent with the finding that the previously validated ${ }^{12}$
Wilks score (Table 1), as used in all IPF events to determine the Champion of Champions, did not differ significantly as a function of body mass of the athletes.

No register was observed regarding doping. The Institutional Department responsible for the study approved the research protocol, and participants received verbal and written information 
about the study and gave written informed consent before assessments. The study received Approval of Institutional Ethics Committee from the Department of Physical Activity Sciences from the University of Los Lagos (Annex II, Act 8/8/2018).

\section{Procedures}

\section{Anthropometric measurements}

According to previous recommendations ${ }^{13}$, and using a method previously validated for males and females ${ }^{14}$, the athletes height was measured using a stadiometer (Bodymeter 206; SECA, Hamburg, Germany), and the body mass and composition with an electrical bioimpedance scale (InBody120, model BPM040S12F07, Biospace, Inc., Seoul, Korea). Briefly, all participants were measured three times, with differences $\leq 0.4 \mathrm{~kg}$ or $0.1 \mathrm{~cm}$ between measures. A multi-frequency bioelectrical impedance analysis device, recommended for trained athletes ${ }^{28}$, with an eight-point tactile electrode system (Inbody 120, Biospace Corp., Seoul, Korea) was used to measure body composition ${ }^{29}$, as described in previous studies ${ }^{14,30}$. The equipment produces 10 impedance values, using frequencies of 20 and $100 \mathrm{kHz}$, measuring right and left leg and arm, and the trunk.

After entering the sex, age and height data into the software, participants maintain a stable position with toes and heels on the anterior and posterior electrodes of the platform, respectively. Assessments started when participants positioned their thumbs on the electrode-handle. An electric current was supplied from the toe tips of both feet and the fingertips of both hands, and the voltage was measured on the heel of both feet and the thenar area of both hands. An inbuilt equation converts the input impedance to body composition estimates, calculated by using the manufacturer's software (Lookin'Body 120, Biospace Corp., Seoul, Korea).

An experienced anthropometrist measured all the 19 anthropometric variables. The anthropometric measures used in this study included trunk fat $(\mathrm{kg})$, trunk lean mass $(\mathrm{kg})$, right leg lean mass $(\mathrm{kg})$, left leg lean mass $(\mathrm{kg})$, right leg fat mass $(\mathrm{kg})$, left leg fat mass $(\mathrm{kg})$, right arm lean mass $(\mathrm{kg})$, left arm lean mass $(\mathrm{kg})$, right arm fat mass $(\mathrm{kg})$, left arm fat mass $(\mathrm{kg})$, total body bone mineral mass $(\mathrm{kg})$, total body protein content $(\mathrm{kg})$, total body water (L), total body fat (\%), total body fat mass $(\mathrm{kg})$, height $(\mathrm{m})$, body mass $(\mathrm{kg})$, and body mass index (BMI, $\mathrm{kg} / \mathrm{m}^{-2}$ ).

In accordance with previous studies ${ }^{15}$, the intraclass correlation coefficient for the measurements was always $\geq 0.89$. However, for body mass, the official value obtained during the powerlifting competition was used for analysis, obtained according to the IPF rules ${ }^{11}$. In this sense, each lifter was weighed only once. Only those whose bodyweight was heavier or lighter than the category limits of the category entered were allowed to return to the scales. They return to the scales and make weight within the limits of the hour and a half allowed for the weighin; otherwise, they were eliminated from the competition (no cases were recorded in this study). A lifter was re-weighed only as often as time and orderly progression by lots allows. A lifter was weighed outside the time limit of one and a half hours if he presented himself within the time limit but due to the number of lifters trying to make weight, he was denied the opportunity of mounting the scales. The lifters then were allowed one re-weigh at the discretion of the referees. The lifter's agreed bodyweight must not be made public until all lifters competing in the particular category/categories were weighed in.

\section{Statistical Analyses}

Except if stated differently, results were expressed as means \pm standard deviations, including minimum and maximum values. The Shapiro-Wilk and Levene's tests yielded non-significant values for all data. Therefore, a one-way ANOVA test was used to determine whether significant inter-group differences occurred for the dependent variables, with post-hoc Fisher test used to determine which groups were initially different. Pearson correlations were run between lifting performance measures and anthropometric measures. As an important number of statistical comparisons were performed, increasing the likelihood of a Type I error, the statistical significance was set at $\mathrm{p}<0.01$. Statistical analyses were via STATISTICA statistical package (Version 8.0; StatSoft, Inc, Tulsa).

\section{Results}

Powerlifters' body composition characteristics are displayed in table 2 and table 3.

Table 2. Body composition characteristics of male and female powerlifters according to weight classes.

\begin{tabular}{|c|c|c|c|c|c|c|c|c|c|c|}
\hline & \multicolumn{2}{|c|}{$\begin{array}{l}\text { Lightweight } \\
\text { males }(n=18)\end{array}$} & \multicolumn{2}{|c|}{$\begin{array}{l}\text { Middleweight } \\
\text { males }(\mathrm{n}=12)\end{array}$} & \multicolumn{2}{|c|}{$\begin{array}{l}\text { Heavyweight } \\
\text { males }(n=10)\end{array}$} & \multicolumn{2}{|c|}{$\begin{array}{l}\text { Lightweight } \\
\text { females }(n=8)\end{array}$} & \multicolumn{2}{|c|}{$\begin{array}{c}\text { Middleweight } \\
\text { and heavyweight } \\
\text { females }(n=8)\end{array}$} \\
\hline & Mean & SD & Mean & SD & Mean & SD & Mean & SD & Mean & SD \\
\hline Body mass (kg) & 70.7 & 3.1 & 87.1 & 5.2 & $107.7^{\mathrm{A}, \mathrm{B}, \mathrm{C}}$ & 7.9 & 49.4 & 3.3 & $63.7^{\mathrm{D}}$ & 9.7 \\
\hline Height $(\mathrm{cm})$ & $168.0^{\mathrm{E}}$ & 7.3 & $174.7^{\mathrm{A}, \mathrm{E}}$ & 4.8 & $172.6^{\mathrm{E}}$ & 4.7 & 154.3 & 2.5 & 164.3 & 4.9 \\
\hline Body mass index $\left(\mathrm{kg} \cdot \mathrm{m}^{-2}\right)$ & 24.8 & 2.2 & $28.6^{\mathrm{A}}$ & 2.5 & $36.3^{\mathrm{A}, \mathrm{B}, \mathrm{C}, \mathrm{E}}$ & 4.0 & $20.4^{\mathrm{B}, \mathrm{C}}$ & 1.3 & $23.7^{\mathrm{B}, \mathrm{C}}$ & 2.9 \\
\hline Trunk fat mass $(\mathrm{kg})$ & $6.0^{\mathrm{C}}$ & 2.9 & $9.0^{\mathrm{C}}$ & 4.1 & 19.0 & 3.5 & $4.8^{\mathrm{C}}$ & 1.1 & $8.5^{\mathrm{C}}$ & 4.7 \\
\hline
\end{tabular}

(To be continued) 
Table 2. Body composition characteristics of male and female powerlifters according to weight classes.

\begin{tabular}{|c|c|c|c|c|c|c|c|c|c|c|}
\hline & \multicolumn{2}{|c|}{$\begin{array}{l}\text { Lightweight } \\
\text { males }(n=18)\end{array}$} & \multicolumn{2}{|c|}{$\begin{array}{l}\text { Middleweight } \\
\text { males }(n=12)\end{array}$} & \multicolumn{2}{|c|}{$\begin{array}{l}\text { Heavyweight } \\
\text { males }(n=10)\end{array}$} & \multicolumn{2}{|c|}{$\begin{array}{c}\text { Lightweight } \\
\text { females }(n=8)\end{array}$} & \multicolumn{2}{|c|}{$\begin{array}{c}\text { Middleweight } \\
\text { and heavyweight } \\
\text { females }(n=8)\end{array}$} \\
\hline & Mean & SD & Mean & SD & Mean & SD & Mean & SD & Mean & SD \\
\hline Trunk lean mass (kg) & $27.1^{\mathrm{E}}$ & 1.6 & $33.1^{\mathrm{A}, \mathrm{E}}$ & 2.7 & $35.1^{\mathrm{A}, \mathrm{E}}$ & 2.1 & 17.2 & 0.9 & 21.4 & 2.4 \\
\hline Left leg fat mass (kg) & $1.7^{\mathrm{C}}$ & 0.5 & $2.0^{\mathrm{C}}$ & 0.8 & 3.9 & 0.7 & $1.7^{\mathrm{C}}$ & 0.3 & $2.5^{\mathrm{C}}$ & 1.1 \\
\hline Left leg lean mass $(\mathrm{kg})$ & $8.5^{\mathrm{E}}$ & 1.0 & $10.1^{\mathrm{A}, \mathrm{E}}$ & 0.8 & $10.5^{\mathrm{A}, \mathrm{E}}$ & 0.5 & 5.5 & 0.4 & 7.1 & 1.0 \\
\hline Right leg fat mass (kg) & $1.7^{\mathrm{C}}$ & 0.6 & $2.0^{\mathrm{C}}$ & 0.8 & 4.0 & 0.7 & $1.7^{\mathrm{C}}$ & 0.3 & $2.5^{\mathrm{C}}$ & 1.1 \\
\hline Right leg lean mass (kg) & $8.5^{\mathrm{E}}$ & 0.9 & $10.1^{\mathrm{A}, \mathrm{E}}$ & 0.8 & $10.5^{\mathrm{A}, \mathrm{E}}$ & 0.5 & 5.5 & 0.5 & 7.1 & 1.1 \\
\hline Left arm fat mass $(\mathrm{kg})$ & $0.5^{\mathrm{C}}$ & 0.4 & $0.7^{\mathrm{C}}$ & 0.5 & 2.2 & 1.2 & $0.6^{\mathrm{C}}$ & 0.1 & $1.1^{\mathrm{C}}$ & 0.7 \\
\hline Left arm lean mass (kg) & $3.5^{\mathrm{E}}$ & 0.3 & $4.6^{\mathrm{A}, \mathrm{E}}$ & 0.5 & $4.9^{\mathrm{A}, \mathrm{E}}$ & 0.4 & 1.8 & 0.1 & 2.5 & 0.4 \\
\hline Right arm fat mass (kg) & $0.5^{\mathrm{C}}$ & 0.4 & $0.7^{\mathrm{C}}$ & 0.5 & 2.5 & 1.0 & $0.6^{\mathrm{C}}$ & 0.1 & $1.1^{\mathrm{C}}$ & 0.7 \\
\hline Right arm lean mass (kg) & $3.5^{\mathrm{E}}$ & 0.3 & $4.5^{\mathrm{A}, \mathrm{E}}$ & 0.5 & $4.9^{\mathrm{A}, \mathrm{E}}$ & 0.4 & 1.9 & 0.1 & 2.5 & 0.4 \\
\hline $\begin{array}{l}\text { Total body bone mineral } \\
\text { content }(\mathrm{kg})\end{array}$ & $3.8^{\mathrm{D}}$ & 0.3 & $4.7^{\mathrm{A}, \mathrm{E}}$ & 0.4 & $4.8^{\mathrm{A}, \mathrm{E}}$ & 0.3 & 2.6 & 0.2 & 3.3 & 0.4 \\
\hline Total body protein content $(\mathrm{kg})$ & $11.7^{\mathrm{E}}$ & 0.8 & $14.3^{\mathrm{A}, \mathrm{E}}$ & 1.2 & $14.9^{\mathrm{A}, \mathrm{E}}$ & 0.6 & 7.6 & 0.4 & 9.4 & 1.2 \\
\hline Total body water (L) & $42.7^{\mathrm{E}}$ & 3.1 & $52.4^{\mathrm{A}, \mathrm{E}}$ & 4.5 & $54.6^{\mathrm{A}, \mathrm{E}}$ & 2.0 & 27.9 & 1.5 & 34.7 & 4.2 \\
\hline Total body fat (\%) & 16.4 & 6.5 & 18.0 & 7.2 & $30.8^{\mathrm{A}, \mathrm{B}}$ & 4.3 & 21.5 & 2.4 & 25.3 & 9.4 \\
\hline Total body fat (kg) & $11.5^{\mathrm{C}}$ & 4.7 & $15.9^{\mathrm{C}}$ & 6.6 & 33.4 & 7.0 & $10.5^{\mathrm{C}}$ & 1.9 & $16.8^{\mathrm{C}}$ & 8.3 \\
\hline
\end{tabular}

A: different $(p<0.05)$ compared to males lightweight; B: different $(p<0.05)$ compared to males middleweight; $C$ : different ( $<<0.05)$ compared to males heavyweight; D: different $(p<0.05)$ compared to lightweight females; E: different $(p<0.05)$ compared to all groups of females.

Table 3. Body composition characteristics of male and female powerlifters.

\begin{tabular}{|c|c|c|c|c|c|}
\hline & \multicolumn{2}{|c|}{$\begin{array}{l}\text { Males } \\
(n=40)\end{array}$} & \multicolumn{2}{|c|}{$\begin{array}{c}\text { Females } \\
(n=16)\end{array}$} & \multirow{2}{*}{$\begin{array}{c}P \\
\text { value }\end{array}$} \\
\hline & Mean & SD & Mean & SD & \\
\hline Body mass (kg) & 84.9 & 16.1 & 56.5 & 10.2 & $<0.001$ \\
\hline Height (cm) & 171.3 & 6.4 & 159.3 & 6.5 & $<0.001$ \\
\hline Body mass index $\left(\mathrm{kg} \cdot \mathrm{m}^{-2}\right)$ & 29.0 & 5.5 & 22.0 & 2.7 & $<0.01$ \\
\hline Trunk fat mass (kg) & 10.4 & 6.4 & 6.6 & 3.7 & 0.2 \\
\hline Trunk lean mass (kg) & 31.1 & 4.2 & 19.3 & 2.8 & $<0.001$ \\
\hline Left leg fat mass (kg) & 2.4 & 1.1 & 2.1 & 0.8 & 0.6 \\
\hline Left leg lean mass (kg) & 9.5 & 1.2 & 6.3 & 1.1 & $<0.001$ \\
\hline Right leg fat mass (kg) & 2.4 & 1.2 & 2.1 & 0.8 & 0.6 \\
\hline Right leg lean mass (kg) & 9.5 & 1.2 & 6.3 & 1.2 & $<0.001$ \\
\hline Left arm fat mass $(\mathrm{kg})$ & 1.0 & 1.0 & 0.8 & 0.5 & 0.7 \\
\hline Left arm lean mass (kg) & 4.2 & 0.7 & 2.2 & 0.4 & $<0.001$ \\
\hline Right arm fat mass $(\mathrm{kg})$ & 1.1 & 1.0 & 0.8 & 0.5 & 0.6 \\
\hline Right arm lean mass (kg) & 4.2 & 0.7 & 2.2 & 0.4 & $<0.001$ \\
\hline $\begin{array}{l}\text { Total body bone mineral } \\
\text { content }(\mathrm{kg})\end{array}$ & 4.3 & 0.6 & 2.9 & 0.5 & $<0.001$ \\
\hline Total body protein content $(\mathrm{kg})$ & 13.4 & 1.7 & 8.5 & 1.3 & $<0.001$ \\
\hline Total body water $(\mathrm{L})$ & 48.9 & 6.3 & 31.3 & 4.7 & $<0.001$ \\
\hline Total body fat (\%) & 20.7 & 8.6 & 23.4 & 6.5 & 0.5 \\
\hline Total body fat (kg) & 18.6 & 10.9 & 13.6 & 6.4 & 0.3 \\
\hline
\end{tabular}

Middleweight males were taller $(\mathrm{p}<0.01)$ than lightweight males and all the groups of females. All groups of males were taller $(p<0.01)$ than the whole group of females. Lightweight females were shorter $(p<0.01)$ than lightweight, heavyweight and the whole group of males. When females from the lightweight and middle-heavyweight classes were compared for height, although a non-significant difference was observed between the groups ( $p=0.05)$, a difference of $\sim 10 \mathrm{~cm}$ in the mean values of the female groups was observed.

Heavyweight males had greater $(\mathrm{p}<0.01)$ BMI compared to rest of the groups. Lightweight males had lower $(p<0.01)$ BMI compared to rest of the male groups. Lightweight females had lower $(\mathrm{p}<0.01)$ BMI compared to the male groups (except for the lightweight males). Middleweight-heavyweight females had lower $(\mathrm{p}<0.01)$ BMI compared to the total sample of males. The total sample of females had lower $(\mathrm{p}<0.01)$ BMI compared to middleweight and the total sample of males. Heavyweight males had greater $(p<0.01)$ percent of total body fat compared to rest of the male groups.

Regarding fat mass for trunk, right and left leg, right and left arm, and total body, the heavyweight males had greater $(\mathrm{p}<0.01)$ values compared to the rest of the groups. Lightweight males also had lower $(p<0.01)$ values than the total sample of males (except for left arm fat mass).

Regarding trunk lean mass, left and right arm and leg lean mass, total body protein, total body water, and total bone mineral mass, in general, all male groups had greater $(\mathrm{p}<0.01)$ values than the groups of females. Lightweight males had lower $(p<0.01)$ values than the rest of male groups. Heavyweight males had greater $(p<0.01)$ values than the total sample of males (except for left and right leg lean mass, and bone mineral content).

In males, squat performance was significantly correlated $(\mathrm{p}<0.01)$ with all anthropometric measures $(\mathrm{r}=0.82-0.66)$, except total body bone mineral content and height. Similarly, bench press performance was significantly correlated $(p<0.01)$ with all anthropometric measures $(r=0.83-0.66)$, except left leg muscle mass, total body bone mineral content, and height. In addition, deadlift performance was significantly correlated $(\mathrm{p}<0.05)$ with all anthropometric measures $(r=0.81-0.64)$, except total body fat 
and height. In contrast, among females, squat performance and bench press performance were not related to any anthropometric variable. Only for deadlift performance a significant correlation was observed for some anthropometric variables ( $\mathrm{r}=0.98-0.54)$, although not for trunk fat mass, left and right leg and arm fat mass, relative and absolute total body fat.

\section{Discussion}

The aim of the present study was to examine how body composition of competitive male and female Chilean powerlifters may differ as a function of body mass and sex. In male powerlifters, as expected, a significant correlation was observed between lifting performance and anthropometric measures. Specifically, body composition variables relating to the accumulation of lean mass and fat increased from lightweight to middleweight to heavyweight, and this was in line with increased absolute 1RM lifting performance, especially for upper-body strength. However, in female powerlifters, the difference between weight classes was not observed for body composition nor for competitive lifting performance, either expressed in absolute terms or as assessed by the Wilks score. Current results are novel, and expand the limited literature previously reported for Latin-American powerlifters 10, suggesting a role for body composition in powerlifting performance depending on sex.

Male and female powerlifters showed high muscularity, with a high proportion of lean mass per unit of body height. This finding is similar to those previously reported for male and female powerlifters ${ }^{1-5,16}$, observing up to $69 \mathrm{~kg}$ of lean mass in males and $45 \mathrm{~kg}$ in females. The heavyweight male lifters had greater values than the total sample of males. In addition, all male groups had greater lean mass values than the groups of females. Such findings are similar to those previously reported for powerlifters and other strength-trained athletes ${ }^{1,5,17}$. In addition, upper-body lean mass was greater among heavier powerlifters than lighter athletes, although left and right leg lean mass in the current study was similar across all weight classes. The greater muscular development of the upper than lower-body may reflect a comparatively greater trained status of the upper-body in the heavier athletes, leading towards greater lean mass and absolute performance. In fact, absolute 1RM performance in the bench press was significantly increased from the lightweight toward the heavyweight male class, whether this was not the case for the absolute 1RM performance of the squat and deadlift exercises which are more reliant on force production from the lower limbs. Such a result appeared somewhat inconsistent with previous studies that found body mass related increases in squat and deadlift absolute $1 \mathrm{RM}^{9,10}$. As our results indicate, the inter-study differences may reflect the tendency for the Chilean middleweight and heavyweight male lifters to have a more absolute trunk but not leg lean mass than the lightweight male lifters.

As hypothesized, heavier male powerlifters had greater absolute levels of lean mass and adiposity than the lighter lifters, as in other bodyweight-classes sports ${ }^{18}$ and powerlifting ${ }^{1}$. In this sense, powerlifters, to lift greater absolute loads, typically increases $1 \mathrm{RM}$ performance in conjunction with the majority of these anthropometric characteristics ${ }^{1-3,6}$. However, a novel finding of the present study was the lack of general difference between female's weight classes for lean mass and adiposity, in line with the lack of differences in 1RM performance in the three competitive lifts. However, for a better interpretation of the results observed in female athletes, it must be considered that for somebody composition variables, although non-significant differences were observed, some practical differences emerged. Regarding trunk fat mass in females, although the middle-heavyweight class group had almost twice fat compared to the middleweight group, the difference between the groups $(\mathrm{p}=0.3)$ was not significant, probably due to the high heterogeneity of the female athletes and the large standard differences between the groups. These findings reinforce the notion of the relationship between 1RM performance in powerlifting and body composition for male athletes and cast doubt regarding the potential underlying factors that lead toward different findings in females.

One potential explanation is the lower number of females participants, which may have reduced the statistical power. To reduce this potential limitation, and taking into account the IPF rules ${ }^{11}$ and the recommendations of previous studies ${ }^{1,2}$, we deemed adequate to mix middleweight and heavyweight females in one group in order to increase the statistical power. However, powerlifting in Chile is not as popular in females as it is among males. Therefore, as the current study was carried out during the most important powerlifting competition event held in Chile, and a relatively low number of females attended at such an event, we were able to recruit a relatively low number of females compared to males. This was especially true among the heavier weight classes, which, among other factors, may reflect the relatively low body mass and height of Chilean females compared to those from Western countries ${ }^{19}$. In this sense, considering the descriptive-exploratory nature of the current study, and due to the potentially different anthropometric characteristics of different ethnic groups, current results offer great potential value so that the data may be used for athlete's talent identification and training program monitoring. In this sense, while previous studies have been conducted in male ${ }^{1,2}$ and female powerlifters ${ }^{9}$, these studies have collected data from Western countries, with only one study reported for Latin-American powerlifters ${ }^{10}$. Although current results offer novel findings, future studies should strive to increase the sample of females (and males) from different weight classes to contrast current findings and establish normative values.

All male groups had greater values of total bone mineral content than the groups of the females, while lightweight males had lower values than the rest of the male groups. The greater bone mass may allow greater lean mass per height unit ${ }^{3,6}$, and may help to better tolerate the compressive and shear forces powerlifting exercises impose on the body during training and competition $^{20}$. This, in turn, may help athletes to reduce injury risk and the associated loss of training time, improve training and competitive performance ${ }^{21}$. Although the method used in the current study to measure bone mass have been previously recommended $^{22}$, we acknowledge that the validity of the method to assess bone mass has been very recently questioned ${ }^{23}$. This should be considered for the interpretation of current results, 
and future studies may be needed using gold-standard methods for the assessment of bone mass.

Middleweight males were taller than lightweight males and all the groups of females. In addition, all the groups of males were taller than the whole group of females. Moreover, as in previous studies 1 , heavier powerlifters were significantly taller than lighter lifters, although the mean height of the middleweight and heavyweight lifters was virtually identical, even though their mean body mass differed significantly. While similar height among powerlifters of different categories may be common ${ }^{1}$, these findings contrast with results from other sports where athletes compete in bodyweight categories ${ }^{18,24,25}$. Although a greater height may be related with greater body mass and lean mass in other sports, in powerlifters this relationship may plateau at $\sim 170 \mathrm{~cm}^{1,26}$, a height similar to the middleweight and heavyweight male lifters in the current study (i.e., $\sim 1.74 \mathrm{~cm}$ ). As the relationship between lean mass and height $\geq 170 \mathrm{~cm}$ is reduced, for a given height, powerlifters may benefit from a large skeletal structure for the accumulation of high levels of lean mass. This agrees with our results, where greater values of bone mass were observed in the heavier powerlifters. However, the increase in lean mass usually is accompanied by an increase in $\mathrm{fat}^{27}$. This was also observed in our study. Therefore, usually, a greater lean mass is associated with a greater competitive performance but also with a greater fat mass.

Of note, athletes in this study were assessed during their peak performance period, corresponding with their most important annual competition, the Chilean powerlifting championship. In this sense, our results are novel, reflecting the body composition of male and female Chilean powerlifters in their peak of performance. Moreover, current body composition values were collected together with athlete's 1RM performance during the powerlifting championship, allowing the establishment of relationships between body composition and competitive performance, for both male and females Chilean powerlifters for the first time.

A potential limitation of the current study deals with the relatively low number of females participating in the Chilean powerlifting championship. Due to the low-lack of females in 5 of the 7 competition weight classes, female athletes were further divided on a lightweight class ( $52 \mathrm{~kg}$ and below), while middleweight (from $52.01 \mathrm{~kg}$ up to $72 \mathrm{~kg}$ ) and heavyweight (from $72.01 \mathrm{~kg}$ and over) female classes were mixed. In this sense, although it would have been ideal to separate the different weight classes for a more comprehensive comparison, in order to increase the statistical power, females were grouped together with a very large range in body weight. This limitation should be acknowledged in the interpretation of current results and future studies should strive to incorporate a greater number of female participants into each weight class.

\section{Conclusion}

In conclusion, heavier lifters had significantly greater lean mass and fat mass than lighter athletes. Therefore, powerlifting performance was affected by anthropometric measures, as corroborated by 1RM scores and correlation analyses. However, there was a general lack of differences in body composition between female weight classes, and, as a result, a lack of differences in 1RM performance.

\section{References}

1. Keogh JW, Hume PA, Pearson SN, Mellow P. Anthropometric dimensions of male powerlifters of varying body mass. J Sports Sci. 2007; 25(12):1365-1376.

2. Brechue WF, Abe T. The role of FFM accumulation and skeletal muscle architecture in powerlifting performance. Eur J Appl Physiol. 2002; 86(4):327-336.

3. Mayhew J, McCormick TP, Piper FC, Kurth AL, Arnold MD. Relationships of Body Dimensions to Strength Performance in Novice Adolescent Male Powerlifters. Pediatr. Exerc. Sci. 1993; 5(4):347-356.

4. Johnson GO, Housh TJ, Powell DR, Ansorge CJ. A physiological comparison of female body builders and power lifters. J Sports Med Phys Fitness. 1990; 30(4):361-364.

5. Katch VL, Katch FI, Moffatt R, Gittleson M. Muscular development and lean body weight in body builders and weight lifters. Med Sci Sports Exerc. 1980; 12(5):340-344.

6. Mayhew JL, Piper FC, Ware JS. Anthropometric correlates with strength performance among resistance trained athletes. J Sports Med Phys Fitness. 1993; 33(2):159-165.

7. Huygens W, Claessens AL, Thomis M, Loos R, Van Langendonck L, Peeters M, et al. Body composition estimations by BIA versus anthropometric equations in body builders and other power athletes. J Sports Med Phys Fitness. 2002; 42(1):45-55.

8. Marchocka M, Smuk E. Analysis of body build of senior weightlifters with particular regard for proportions. Biology of Sport. 1984; 1:55-71.

9. Keogh JW, Hume PA, Pearson SN, Mellow P. To what extent does sexual dimorphism exist in competitive powerlifters? J Sports Sci. 2008; 26(5):531-541.

10. Lovera M, Keogh J. Anthropometric profile of powerlifters: differences as a function of bodyweight class and competitive success. J Sports Med Phys Fitness. 2015; 55(5):478-487.

11. IPF. International Powerlifting Federation. Technical Rules Book, 2006.

12. Vanderburgh PM, Batterham AM. Validation of the Wilks powerlifting formula. Med Sci Sports Exerc. 1999; 31(12):1869-1875.

13. Norton K, Olds T. Anthropometrica, Sydney, Australia, University of New South Wales Press; 1996.

14. Anderson LJ, Erceg DN, Schroeder ET. Utility of multifrequency bioelectrical impedance compared with dual-energy x-ray absorptiometry for assessment of total and regional body composition varies between men and women. Nutrition research (New York, N.Y.). 2012; 32(7):479-485.

15. Buckinx F, Reginster JY, Dardenne N, Croisiser JL, Kaux JF, Beaudart $\mathrm{C}$, et al. Concordance between muscle mass assessed by bioelectrical impedance analysis and by dual energy X-ray absorptiometry: a cross-sectional study. BMC Musculoskelet Disord. 2015; 16:60. 
16. Bale $\mathrm{P}$, Williams $\mathrm{H}$. An anthropometric prototype of female power lifters. J Sports Med Phys Fitness. 1987; 27(2):191-196.

17. Silva PRPd, Trindade RdS, De Rose EH. Composição corporal, somatotipo e proporcionalidade de culturistas de elite do Brasil. Revista Brasileira de Medicina do Esporte. 2003; 9:403-407.

18. Orvanova E. Somatotypes of weight lifters. J Sports Sci. 1990; 8(2):119-137.

19. NCD Risk Factor Collaboration (NCD-RisC). A century of trends in adult human height. eLife. 2016; 5, pii: e13410. doi: 10.7554/ eLife. 13410.

20. Escamilla RF, Lander JE, Garhammer J. Biomechanics of powerlifting and weightlifting exercises, in Exercise and sport science. Garrett WE, Kirkendall DT, ed`eds. Philadelphia, PA, Lippincott Williams \& Wilkins, 2000.

21. Keogh J, Hume PA, Pearson S. Retrospective injury epidemiology of one hundred one competitive Oceania power lifters: the effects of age, body mass, competitive standard, and gender. J Strength Cond Res. 2006; 20(3):672-681.

22. Gazarova M, Meciarova L, Kopcekova J, Holovicova M, Habanova M, Bronkowska M. Comparison of selected parameters of body composition in a group of sporting and non-sporting women. Roczniki Panstwowego Zakladu Higieny. 2018; 69(3):257-266.

23. Beato GC, Ravelli MN, Crisp AH, de Oliveira MRM. Agreement Between Body Composition Assessed by Bioelectrical Impedance Analysis and Doubly Labeled Water in Obese Women Submitted to Bariatric Surgery : Body Composition, BIA, and DLW. Obesity surgery. 2018.

24. Pilis W, Wojtyna J, Langfort J, Zajac Z, Manowska B, Chmura J, et al. Relationships between sport results, somatic variables and anaerobic power in elite weight lifters. Biology of Sport. 1997; 14:275-281.

25. Sodhi HS. Physique of top-ranking Indian wrestlers. J Sports Med Phys Fitness. 1983; 23(1):59-66.

26. Abe T, Brechue WF, Fujita S, Brown JB. Gender differences in FFM accumulation and architectural characteristics of muscle. Med Sci Sports Exerc. 1998; 30(7):1066-1070.
27. Forbes GB. Lean body mass-body fat interrelationships in humans. Nutrition reviews. 1987; 45(8):225-231.

28. Moyer, M. NWCA Wrestling Validation Study. National Wrestling Coaches Association, 2017. http://www.nwcaonline.com/wp-content/uploads/2017/11/NWCA-Validation-Summary-2017.pdf.

29. Biospace Co., Ltd. InBody User's Manual, 1996. http://www. inbody.cz/manual_lookinbody120.pdf.

30. Lee LW, Liao YS, Lu HK, Hsiao PL, Chen YY, Chi CC, Hsieh KC. Validation of two portable bioelectrical impedance analyses for the assessment of body composition in school age children. PLoS ONE 2017, 12(2), e0171568.

\section{Acknowledgments}

The authors thank all the athletes who volunteered to participate in the study and those who collaborated with data collection.

\section{Corresponding author}

Dr. Rodrigo Ramirez-Campillo

Department of Physical Activity Sciences. Universidad de Los Lagos (University of Los Lagos).

Av. Fuschlocher 1305, Osorno, CHILE.

Email: r.ramirez@ulagos.cl

Manuscript received on July 4, 2018

Manuscript accepted on November 7, 2018

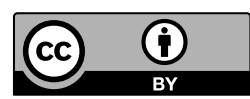

Motriz. The Journal of Physical Education. UNESP. Rio Claro, SP, Brazil - eISSN: 1980-6574 - under a license Creative Commons - Version 4.0 